\title{
PERFIL DO INGRESSANTE: LICENCIATURA EM PEDAGOGIA A DISTÂNCIA NO ÂMBITO DA UNIVERSIDADE DO OESTE PAULISTA (UNOESTE)
}

\author{
Danielle Aparecida do Nascimento dos Santos. Dayene Miralha de Carvalho Sano \\ Universidade do Oeste Paulista - UNOESTE, Curso de Pedagogia, Núcleo de Educação a Distância (NEAD). Presidente \\ Prudente, SP. E-mail: danielle@unoeste.br
}

\section{RESUMO}

A missão da Unoeste prevê o desenvolvimento de ações educacionais por meio de ambientes inovadores e, entre os seus princípios, propõe acompanhar as constantes transformações da sociedade. A modalidade de Educação a Distância (EaD) é uma realidade latente, especialmente no âmbito do Ensino Superior. Essa modalidade educacional deve compor, segundo a legislação brasileira vigente, a política institucional das Instituições de Ensino Superior, constando do Plano de Desenvolvimento Institucional (PDI), do Projeto Pedagógico Institucional (PPI) e dos Projetos Pedagógicos dos Cursos (PPC). Em 2016 o Curso de Pedagogia - EAD da Unoeste propôs a oferta de formação inicial - licenciatura, a estudantes de Presidente Prudente e região. Como instrumento para mensurar o perfil dos ingressantes previsto no PPC do curso, a Comissão Própria de Avaliação (CPA) aplicou um questionário no primeiro semestre de 2016. Os dados revelam o diferencial do curso em termos da aprendizagem e flexibilidade propostas.

Palavras-chave: Educação a Distância, Licenciatura em Pedagogia, Perfil do Ingressante.

\section{STUDENT PROFILE: PEDAGOGY DISTANCE WITHIN THE PAULISTA WEST UNIVERSITY}

\begin{abstract}
The mission of Unoeste provides for the development of educational programs through innovative environments and, among its principles, proposes monitor the constant changes in society. The mode of Distance Education is a latent reality, especially in the context of higher education. This educational modality should compose, according to Brazilian legislation, the institutional policy of higher education institutions, consisting of the Institutional Development Plan, the Institutional Educational Project and the Pedagogic Projects Course. In 2016 the Pedagogy Course proposed offering initial training - degree in Presidente Prudente students and region. As a tool to measure the profile of entrants provided for in pedagogic project course, the committee for assessment applied a questionnaire in the first half of 2016. The results demonstrate the differential of the course in terms of learning and flexibility proposals.
\end{abstract}

Keywords: Distance Education, Pedagogy Course, Student Profile. 


\section{INTRODUÇÃO}

A formação dos professores é um processo que ocorre em paralelo com o desenvolvimento dos sistemas de ensino e das políticas públicas educacionais, considerando as demandas sociais e econômicas e o contexto global e específico em que estão inseridos (GARCIA, 1999).

Para tanto, é necessária, na formação inicial de professores, uma epistemologia didática que lhes permita compreender o processo de ensino e também como devem ser estabelecidas as relações entre professores, estudantes, conhecimento e recursos pedagógicos e tecnológicos dos quais dispõe para processar o ensino, culminando na aprendizagem.

Além disso, a formação inicial deve oferecer aporte teórico e criar estratégias para que o professor compreenda o ensino. Nesse sentido, o foco deste artigo é uma iniciativa de formação inicial, oferecida no contexto da Educação a Distância (EaD), no âmbito da Licenciatura em Pedagogia.

A formação em Pedagogia, expressa na Resolução n. 2 de 10 de julho de 2015, volta-se à formação para atuar na educação infantil e nos anos iniciais do ensino fundamental, bem como para o ensino médio, educação de jovens e adultos, e gestão escolar.

De acordo com Gatti (2011), mediante a resolução, essa licenciatura passa a ter amplas atribuições que compreendem os primeiros passos na aprendizagem dos estudantes, em uma perspectiva polivalente, sendo exigida uma grande complexidade curricular relacionada à abordagem dos conteúdos de diferentes áreas do conhecimento.

Essa complexidade deve considerar a contribuição para a construção de conhecimentos como filosófico, histórico, antropológico, ambiental-ecológico, psicológico, linguístico, sociológico, político, econômico e cultural. Esses aspectos devem ter como meta o desenvolvimento de habilidades de planejamento, execução, coordenação, acompanhamento e avaliação de projetos e experiências educativas não escolares, que devem ser a base para a formação escolar, e para a produção e difusão do conhecimento científico-tecnológico do campo educacional, em contextos escolares e não escolares.

Diante desse pressuposto, faz-se necessário promover ações de formação inicial de professores nas quais sejam propostas ações de intervenção do futuro professor, ou ainda de que compreenda como ocorre o desenvolvimento do estudante. A formação dos professores é um cenário permanente de conflitos (ENGUITA, 1990), devendo buscar uma educação mais globalizadora e sistêmica.

Para tanto, a formação inicial deve possibilitar um saber-fazer prático que permita ao professor ter a possibilidade de agir nas situações mais complexas de ensino, como, por exemplo, o uso de Tecnologias Digitais de Informação e Comunicação (TDIC).

De acordo com Pellanda, Schlünzen e Schlünzen Junior (2005), a apropriação das TDIC é um caminho fundamental para uma nova cultura planetária e uma nova postura diante da realidade e do conhecimento, pois, com ela, abrem-se possibilidades emancipatórias.

A modalidade de Educação a Distância (EaD) é legitimada pela legislação brasileira (Lei de Diretrizes e Bases da Educação Nacional - LDBEN no 9.394/96), podendo ser oferecida de diferentes maneiras e por muitas razões. Pode ser operacionalizada com momentos presenciais ou não. A diferença é que, nesta modalidade, o contato professor-aprendiz ocorre em um espaço virtual (MORAN, 2002). Com isso, a comunicação tem outro viés e é potencializada pelas TDIC, recursos da Web 2.0 ou pelas ferramentas de um Ambiente Virtual de Aprendizagem (AVA).

Diante dessas premissas, o curso de Pedagogia na modalidade de Educação a Distância (EAD) da Universidade do Oeste Paulista (Unoeste) tem como base a LDBEN no. 9.394/96 e outras leis complementares, bem como a legislação sobre educação a distância em vigor, em especial os Decretos n‥ 5.622 de 19 de dezembro de 2005 e n‥ 6.303 de 13 de dezembro de 2007.

O objetivo do curso é formar profissionais de educação habilitados para atuar na Educação Infantil e nos anos iniciais do Ensino Fundamental, na Gestão Educacional, na Educação Hospitalar 
e Empresarial, na Educação do Campo, Indígena e Quilombola e em projetos educacionais formais e não formais.

Nessa perspectiva sistêmica de formação, em que, entre outros aspectos, o domínio da tecnologia faz-se necessário para a aprendizagem, além da compreensão da gestão acadêmica e do conhecimento gerada em função dessa aprendizagem que deve ser deflagrada, para públicos heterogêneos e com expectativas diferenciadas, o presente artigo visa apresentar os dados presentes no perfil do ingressante, aplicado aos estudantes que participaram da primeira oferta do curso de Pedagogia - EAD da Unoeste, no primeiro semestre de 2016.

\section{METODOLOGIA}

A pesquisa tem natureza qualitativa. A metodologia empregada foi a documental e bibliográfica, tendo como fontes de dados os documentos institucionais e o Projeto Pedagógico de Curso (PPC), bem como referenciais sobre os temas centrais formação inicial, licenciatura em Pedagogia e educação a distância.

Para levantamento do perfil do ingressante usou-se a técnica de coleta de dados, questionário estruturado. De acordo com Marconi e Lakatos (1999), o questionário é um instrumento de coleta de dados constituído por uma série de perguntas, que devem ser respondidas pelo sujeito. Nesse caso, os sujeitos foram os estudantes ingressantes de Pedagogia EAD da Unoeste, que responderam o questionário elaborado pela Comissão Própria de Avaliação (CPA) da Unoeste, disponibilizado pela coordenação de curso no Ambiente Virtual de Aprendizagem (AVA) Aprender Unoeste, na Sala da Coordenação.

Os estudantes tiveram um período de quinze dias para submeterem suas respostas.

\section{RESULTADOS}

O Projeto Pedagógico do Curso (PPC) foi elaborado com a participação do Núcleo Docente Estruturante (NDE), sob a orientação da Coordenação, Aprovação do Colegiado do Curso e Supervisão da Pró-Reitoria Acadêmica, estando em consonância com os princípios e as ideias básicas contidas no Projeto Pedagógico Institucional (PPI) e no Plano de Desenvolvimento Institucional (PDI - 2013/2017).

Em conformidade com o disposto no art. 11 da Lei no. 10.861/04 do Sistema Nacional de Avaliação da Educação (SINAES), a Unoeste constituiu pela Portaria no. 13, de 09 de junho de 2004, sua Comissão Própria de Avaliação (CPA) com as funções de coordenar e articular o processo interno de avaliação da Instituição.

Dentre as suas atribuições, cabe à CPA desenvolver e acompanhar as atividades de avaliação. No desenvolvimento do projeto de autoavaliação institucional, a CPA, compromete docentes, discentes e corpo técnico-administrativo para avaliação das condições gerais de funcionamento de todos os cursos, com relação aos itens: salas de aula, laboratórios, bibliotecas, secretarias, setores administrativos, recursos audiovisuais, instalações para aulas práticas, condições para a realização de pesquisas, atividades físicas, culturais e de extensão, serviços gerais, imagem da instituição, diálogo e comunicação interna, políticas de atendimento aos estudantes, dentre outros.

No contexto do Curso de Pedagogia - EAD, a avaliação é feita como um processo de constante aprimoramento, tanto no que se refere a seu funcionamento quanto à busca do alcance social de suas ações. Desse modo, a primeira etapa de avaliação programada pela CPA, se refere aos aspectos como: Sentimento de inclusão à Unoeste; Apoio na realização das atividades propostas; Ambiente Virtual de Aprendizagem (AVA) Aprender Unoeste; Suporte técnico; Infraestrutura na Sede e nos Polos de Apoio Presencial (salas de aula, laboratórios, bibliotecas etc.); Atuação do corpo docente (professores e tutores); Atuação da coordenação de curso; 
Atuação da coordenação dos Polos de Apoio Presencial; Articulação da equipe pedagógica (professores, tutores e coordenação de curso).

Para tanto, a CPA aplica, semestralmente, um questionário para levantamento do "Perfil do Ingressante". A sequência de histogramas apresentados demonstra os resultados da aplicação do questionário para o curso de Pedagogia. Responderam 100\% dos ingressantes.

\section{DISCUSSÃO}

Diferente do estudante que frequenta cursos de educação superior presenciais, que tem a universidade diariamente ao seu alcance, considerando toda a sua infraestrutura, o estudante de EaD possui um perfil que indica características próprias voltadas à aprendizagem planejada, autonomia, percepção e cognição, que permitem uma grande flexibilidade e possibilidade de que esse estudante combine a sua formação, com seus afazeres e profissão.

Nessa perspectiva, conforme pode-se observar no Gráfico 1 é possível inferir que grande parte dos estudantes optou pela modalidade EaD devido às características presentes na formação proposta nesse tipo de modalidade. O Gráfico revela, ainda, um interesse pela credibilidade conferida à formação ofertada pela instituição, em grande parte pelos resultados excelentes presentes nas avaliações externas e no perfil dos egressos.

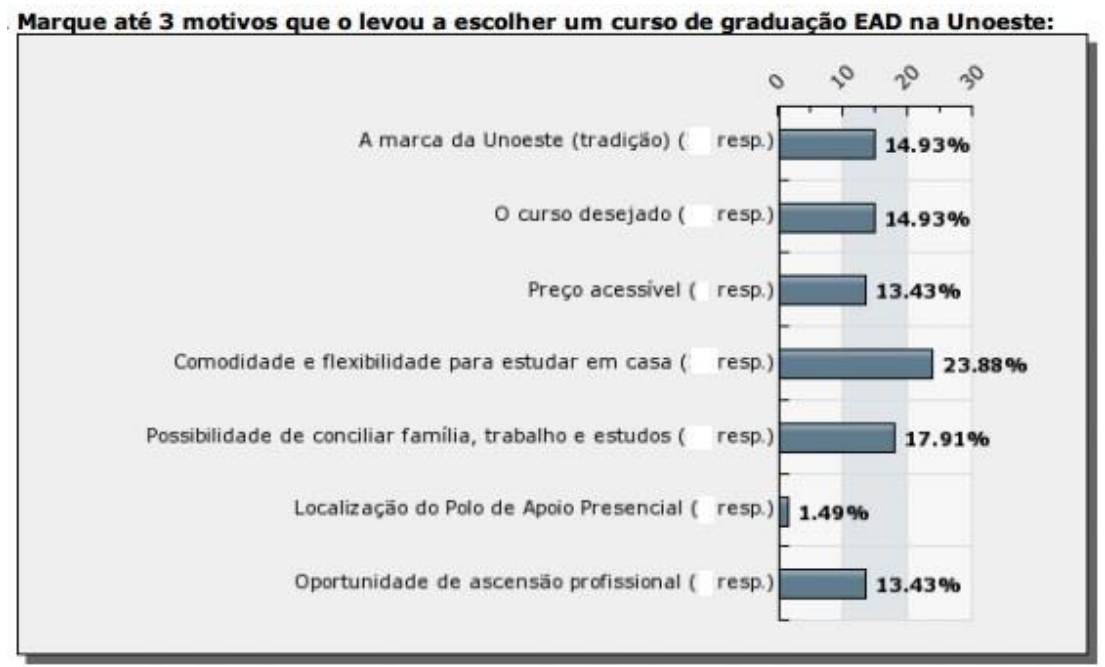

Fonte: Relatório "Perfil do Aluno Ingressante - EAD", 1ำ semestre de 2016 - Comissão Própria de Avaliação (CPA) da Unoeste.

O Gráfico 1 permite compreender, ainda, que o aumento da procura por cursos a distância se dá pelas facilidades que a modalidade oferece.

Em relação ao perfil relacionado a gênero, $100 \%$ dos estudantes matriculados no primeiro semestre de 2016 é do sexo feminino.

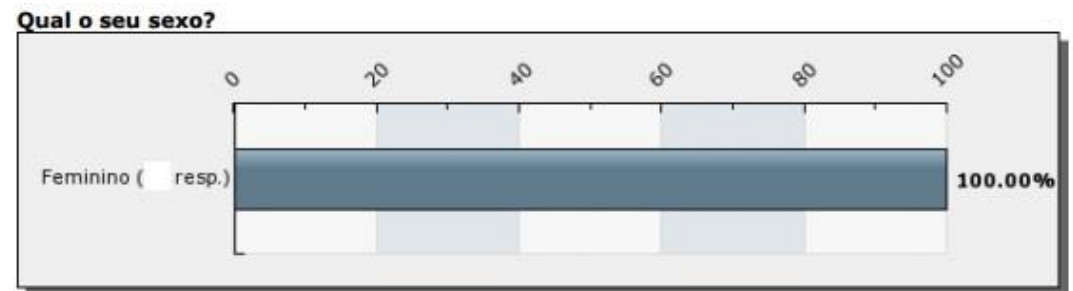

Fonte: Relatório "Perfil do Aluno Ingressante - EAD", 1o semestre de 2016 - Comissão Própria de Avaliação (CPA) da Unoeste. 
O Gráfico 2, acima, revela a busca da mulher por um espaço no mercado de trabalho e que, sendo essas pessoas que possuem uma jornada dupla de trabalho e família (na maioria dos casos), optam por essa modalidade de ensino como uma alternativa eficaz para sanar sua busca pelo conhecimento.

Ainda em relação à autonomia e à aprendizagem planejada, bem como o domínio da tecnologia, verifica-se a partir do Gráfico 3 que a maioria dos estudantes acessa os conteúdos com computador pessoal, do tipo notebook.

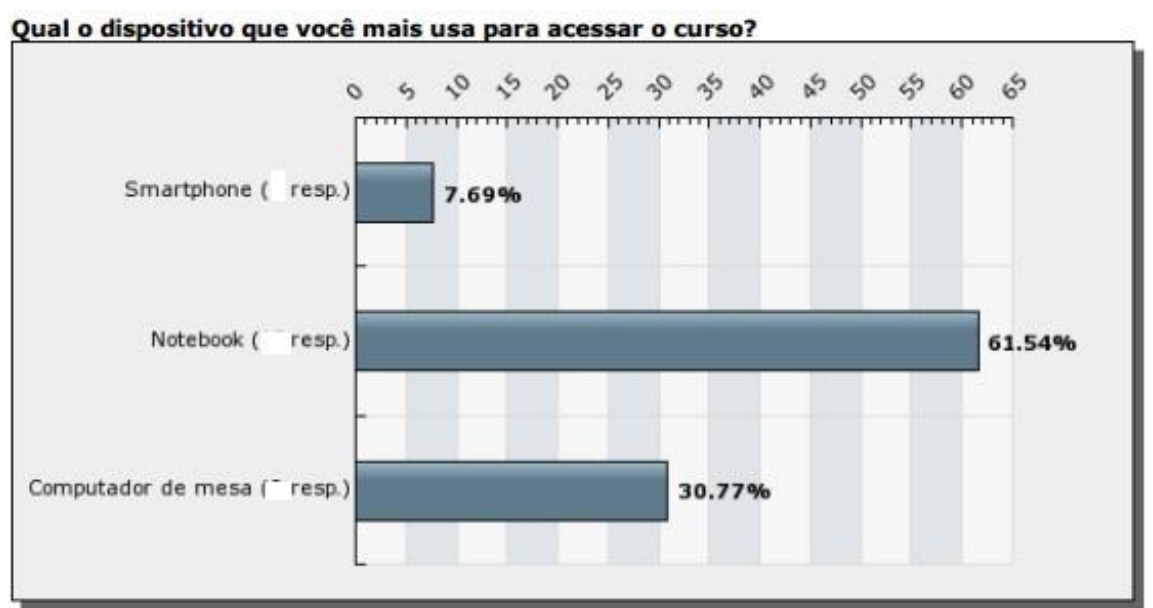

Fonte: Relatório “Perfil do Aluno Ingressante - EAD”, 10 semestre de 2016 - Comissão Própria de Avaliação (CPA) da Unoeste.

Algumas facilidades podem auxiliar esse estudante, e a tecnologia usada é uma delas. Quanto mais amigável a tecnologia, melhores as condições para que o estudante acesse os conteúdos e organize os seus estudos.

Finalmente, em relação à abordagem de EaD adotada pela Unoeste, observa-se que os estudantes compreendem a metodologia, de acordo com o depoimento da Estudante $A^{1}$ :

Acho muito bom e eficaz o método usado pela unoeste na EAD, de estar junto virtual. Pois proporciona uma ótima interação entre os alunos e os professores, fazendo assim com que me sinta dentro de uma sala de aula, literalmente. Espero que seja assim até o final do curso.

De acordo com Valente (2000), o Estar Junto Virtual é uma abordagem de EaD que permite a implantação de situações para a construção de conhecimento, que envolvem o acompanhamento e assessoramento constante do estudante, no sentido de poder entender o que ele faz. Nessa vertente, percebe-se que o curso de Pedagogia - EAD da Unoeste tem possibilitado a vivência de situações de aprendizagem a distância, que potencializam o "estar junto", demonstrando assim que os aspectos relacionados à atuação do corpo docente (professores e tutores), atuação da coordenação de curso, atuação da coordenação dos Polos de Apoio Presencial e articulação da equipe pedagógica (professores, tutores e coordenação de curso) tem gerado impactos positivos nos estudantes.

\section{CONCLUSÃO}

A partir das perspectivas presentes neste artigo, com base nos dados sobre o levantamento do "Perfil do Aluno Ingressante", aplicado pela CPA da Unoeste aos estudantes do curso de Pedagogia - EAD no primeiro semestre de 2016, é possível afirmar que o foco da Unoeste no que

\footnotetext{
${ }^{1}$ Fonte: Relatório “Perfil do Aluno Ingressante - EAD”, 10 semestre de 2016 - Comissão Própria de Avaliação (CPA) da Unoeste.
} 
diz respeito a EaD, atuar no cenário da EaD com o suporte das diversas mídias e de recursos didáticos sistematicamente organizados, a ampliação da infraestrutura adequando-a às necessidades acadêmicas na modalidade a distância, entre outros, tem sido alcançado.

Com isso, a Unoeste passa a ampliar e contribuir com a democratização do acesso à educação formal, por meio da formação de professores para atuar na Educação Básica em diferentes localidades, e atender as demandas da atual sociedade globalizada. Há que se ressaltar que há uma equipe multidisciplinar que dá sustentação a realização de todo o processo educacional, responsável por manter e elaborar os recursos necessários.

Por fim, convém salientar que a infraestrutura física e tecnológica da Unoeste está devidamente adequada para o funcionamento do Sistema de EaD, tanto na Sede quanto nos Polos de Apoio Presencial.

\section{REFERÊNCIAS}

BRASIL. Senado Federal. Lei de Diretrizes e Bases da Educação Nacional: no 9304/96. Brasília: 1996.

GARCIA, C. M. Formação de professores: para uma mudança educativa. Trad. Isabel Narciso. Portugal: Porto editora, 1999.

GATTI, B. A. A prática pedagógica como núcleo do processo de formação de professores. In: CONGRESSO ESTADUAL PAULISTA SOBRE FORMAÇÃO DE EDUCADORES, n. 11., Águas de Lindóia. Anais do Congresso Estadual Paulista sobre Formação de Educadores de 2011. São Paulo: Unesp, 2011.

ENGUITA, F. M. Reprodução, Contradição, estrutura social e atividade humana na educação. Teoria e Educação. Porto Alegre (1): 108-133. Jun 1990.

PELLANDA, N. M. C.; SCHLÜNZEN, E. T. M.; SCHLÜNZEN JUNIOR, K. (Org.). Inclusão digital: tecendo redes afetivas/cognitivas. Rio de Janeiro: DP\&A, 2005.

MORAN, J. M. O que é um bom curso a distância? 2002. Disponível em:

<http://www.eca.usp.br/prof/moran/bom_curso.htm>. Acesso em: 16/08/2016.

MARCONI, M. A.; LAKATOS, E. M. Técnicas de pesquisa: planejamento e execução de pesquisas, amostragens e técnicas de pesquisa, elaboração, análise e interpretação de dados. 2a ed., 1990.

VALENTE, J. A. O computador na sociedade do conhecimento. Campinas: Unicamp/NIED, 2000. 